\title{
A Psicologia Educacional e a Formação de Professores: Tendências Contemporâneas
}

\author{
José Aloyseo Bzuneck ${ }^{1}$ \\ Universidade Estadual de Londrina.
}

\begin{abstract}
Resumo
A Psicologia Educacional é uma das disciplinas da formação acadêmica dos professores, mas é também uma área de pesquisa com implicações para a aprendizagem e o ensino. Ela apresenta um meio para compreensão da complexa tarefa educacional no contexto da sala de aula e sociocultural. Os professores precisam ter uma perspectiva psicológica útil para poderem fazer o melhor em seu trabalho.
\end{abstract}

Palavras chaves: Psicologia Educacional, formação do professor, educação.

\section{Educational Psychology and the Teachers Education: contemporary tendencies}

\section{Summary}

Educational Psychology is one of the disciplines in the academic formation of teachers, but it is also one research area with implication to learning and teaching. It presents a way to understant the complex education task in classroom and in the socio-cultural contexts. The teacher must to have one use fui psychological perspective in order to do the best in their work.

Key words: Educational Psychology, teachers education, education.

O rótulo Psicologia Educacional exprime algum nível de relação da Psicologia com Educação. Essa relação já foi conceituada de diversas formas e sujeita a mal-entendidos. Para começar, é necessário conceituar educação, o que já é uni grande desafio. Para nossos propósitos, vamos aqui considerá-la descritivamente como o conjunto dos esforços de uma sociedade no sentido de socializar as novas gerações em relação à sua herança cultural, através de instituições como a escola, ao lado de outras agências. Isto implica em que a educação, ao menos em parte, varia conforme o lugar e a época.

Se a educação varia conforme o lugar e a época, assim também tem ocorrido com a psicologia educacional. Por um lado, temos hoje problemas similares aos de um século atrás (aprendizagem, motivação...), mas por outro lado, enfrentamos atualmente desafios impensáveis há apenas poucas décadas. Um deles é o número crescente de famílias desfeitas, pobres, não cooperativas com a escola, de adolescentes grávidas, o que vem associado à globalização da economia e das comunicações, a novas exigências do mercado de trabalho, à informática e também à difundida disponibilidade de drogas. Certos desafios são nossos, do Brasil, diferentes dos países do primeiro mundo. Mas, em toda a parte, há fortes indicadores de que a escola está se tornando a instituição educacional mais universal em que todos podem confiar, inclusive com repercussões positivas nas próprias famílias. $\mathrm{Na}$ escola, os alunos, crianças e adolescentes, deverão atingir determinados objetivos educacionais, como adquirir conhecimentos e habilidades, inclusive sociais, desenvolver a moralidade etc. Ora, no âmbito da escola, a ênfase e as expectativas relativamente a resultados educacionais estão recaindo muito sobre o(a) professor(a), aquela pessoa que atende a

${ }^{1}$ Endereço: Rua Rui Barbosa, 187. CEP: 86070-610, Londrina - Paraná - Brasil. 
uma classe de 30-40 alunos, porque é mediante essa pessoa que os alunos poderão atingir aqueles objetivos educacionais. Por isso, a nova visão de educação confia mais nos professores do que nos materiais e na tecnologia, confia em experiências de cada escola que, embora pequenas, concentradas e personalizadas, têm um caráter cooperativo, respondem a problemas locais. Dar conta das exigências educacionais é um processo contínuo de busca, e que é feito por pessoas.

A disciplina de Psicologia Educacional tradicionalmente faz palie da formação dessas pessoas, que são os professores e educadores. Mas essa disciplina se apresenta com facetas múltiplas, o que permitiu que no seu seio se formassem diversas posições ao longo da sua história.

Basicamente, é uma disciplina acadêmica, um campo de pesquisa científica, com profundas relações com a prática educacional, o que significa que toda a construção de seu trabalho consiste em unir a prática da educação escolar com a psicologia científica.

Para começar, a Psicologia Educacional, como campo de conhecimento psicológico-científico, já se firmou como uma disciplina por direito próprio, não se considerando mais como uma simples aplicação da Psicologia aos problemas educacionais. Esta era uma concepção arcaica e viesada. E os psicólogos educacionais são mais do que psicólogos interessados em educação. Numa formulação de Wittrock (1992), os psicólogos educacionais são aqueles que hoje se identificam com o estudo científico da psicologia na educação.

Eu explico essa formulação: toda disciplina científica é, em síntese, uma combinação de problemas, teorias e melado/agias. Na Psicologia Educacional podem ser facilmente identificados estes três componentes, com notável coerência. Os problemas são educacionais; as pesquisas e a produção focalizam problemas significativos da educação. Problemas como: ensino de...; processos cognitivos e afetivos na aprendizagem escolar, incluindo aí os da motivação (motivação é considerada problema de ponta em educação), otimização da aprendizagem dos alunos, estratégias de aprendizagem, aprendizagem auto-regulada, autoconceito, crenças e conhecimentos prévios de alunos e professores, níveis de desenvolvimento do aluno etc. Em todos esses esforços, a Psicologia Educacional tem como sua primeira finalidade a compreensão e a melhora da educação, particularmente no contexto escolar, em sala de aula. Em outras palavras, essa disciplina busca descobrir problemas, situá-los, defini-los e compreendê-los, sinalizando soluções práticas.

Em Psicologia Educacional, quase que para cada tópico, existe ao menos uma teoria. No conjunto, contam-se muitas teorias, cada qual com suas limitações, mas que representam preciosos marcos com os quais se atingem certos objetivos com algum nível de compreensão dos conteúdos e dos resultados de pesquisas. Mesmo que admitamos a proposição de K. Lewin de que nada é mais prático do que uma boa teoria, é sua relação com a prática que mais nos preocupa. É em relação a esse conceito de aplicabilidade que eu pretendo mostrar mais adiante as principais tendências contemporâneas, identificadas nos trabalhos de especialistas na área.

Mas falta um último esclarecimento acerca do terceiro componente, que é a metodologia. A Psicologia Educacional segue os parâmetros de rigor científico como qualquer ciência social. Como sempre, em suas pesquisas, ela busca assegurar o controle das variáveis, através de um delineamento adequado, com a garantia de que as provas são válidas e consistentes, tem cuidado com evitar mal-entendidos conceituais e de interpretação dos resultados. Além de experimentos de laboratório, aplica delineamentos quase-experimentais; em pesquisas que utilizam instrumentos do tipo de auto-relato, hoje adota-se o coeficiente alpha de Cronbach para levantar o grau de consistência interna entre os itens, ao lado de técnicas de análise fatorial, para a identificação dos 
fatores subjacentes aos diferentes itens; além disso, tornam-se mais freqüentes os estudos de metaanálise; por exemplo, há um estudo de meta-análise que analisou todo um conjunto de estudos sobre o uso de recompensas externas e revelou-nos o que esses diversos estudos, com diversas metodologias, critérios etc. concluíram sobre os efeitos das recompensas externas para a motivação intrínseca dos alunos. O aprofundamento veio a seguir, com estudos críticos acerca dessa metaanálise. E assim progride esse campo da psicologia como verdadeira ciência.

Além disso, os conceitos de validade e fidedignidade moveram-se da estatística para a interpretação das evidências. Ainda são muito valorizadas as pesquisas de avaliação quantitativa, mas hoje utilizam-se cada vez mais métodos qualitativos inovadores, derivados da antropologia e da etnografia. Um detalhe quanto às pessoas envolvidas em pesquisa: agora quem lida com metodologia deve também entender dos aspectos substantivos; daí, não pode mais ocorrer como antes, em que os metodólogos não compreendiam os aspectos substantivos e apenas davam respostas a questões de natureza quantitativa. Hoje, as questões substantivas são as que mais contam numa pesquisa, e uma metodologia adequada deve ater-se a essas questões bem específicas (Calfee e Berliner, 1996). Prevê-se, inclusive, segundo esses autores, que num futuro próximo os pesquisadores da área precisarão dominar mais técnicas de pesquisa do que antes, algumas das quais se acham apenas em seu início ou ainda em fase de desenvolvimento.

Em síntese, esse é o quadro que revela o status científico definido da Psicologia Educacional. Nós não precisamos mais ter a preocupação de provar para quem quer que seja que Psicologia Educacional é tão ciência como qualquer outra área da Psicologia. A questão que mais nos atinge e interessa, porém, é esta: em que sentido ela serve para a prática de sala de aula ou, mais amplamente, para a tarefa educadora do professor na escola? Em outras palavras, como se conceitua sua natureza de ciência aplicada?

A todos pode então ocorrer que, como conseqüência de sua característica de ser ciência, um modo adequado de se conceituar corretamente a Psicologia da Educação é através da metáfora tradicional de fundamento. De acordo com esse conceito, ela seria tratada nas nossas aulas como um conjunto de conhecimentos a serem aprendidos pelos futuros professores, a título de base para sua atuação profissional. Neste sentido, a psicologia, como disciplina acadêmica, é uma ferramenta intelectual com a qual se julga a prática, se reflete sobre ela e, como se espera, dirige essa prática. Essa ferramenta intelectual seriam as teorias psicológicas, os princípios, os dados de pesquisa etc. que um acadêmico deveria aprender para, a seu tempo, aplicá-los na sua atuação em sala de aula. Um professor de Psicologia Educacional raciocinaria desta forma: eu domino, apoiado nos livrostexto, um conjunto de informações de psicologia, que vou passar p'ara os alunos de licenciatura. Por suposto, tais conhecimentos lhes serão úteis no ensino que irão desenvolver de suas matérias. Dou exemplos práticos, ilustro, e minha missão está cumprida. Eis aí a concretização da metáfora do fundamento, que foi, de fato, utilizada e aceita ao longo deste século, praticamente sem questionamentos, até os anos 70. Constava dos textos e se refletia, em geral, na produção científica da área.

Mas antes de vermos porque essa metáfora foi questionada e superada, é interessante lembrar alguns lances dos primórdios da psicologia científica, que provavelmente explicam a origem dessa metáfora. No passado, no seio da academia, havia uma ênfase na pesquisa psicológica enquanto tal, em detrimento de outros aspectos tipicamente educacionais. Havia, sim, interesse pela educação, porém, a Psicologia Educacional não se identificava com a formação de professores. Na ânsia por 
status no seio da comunidade científica, aqueles pesquisadores isolaram a pesquisa da prática e dos que praticam. O laboratório, em vez da sala de aula, era o lugar da pesquisa, e o objeto dos estudos eram questões como o movimento dos olhos ao ler, ou a memória de sílabas sem sentido. Essa opção era justificada em parte, para se ficar alinhado com as ciências exatas como física, e assim participar de uma linha de pensamento considerada progressista, moderna. A origem dessa tendência é atribuída a Judd e a Thorndike. Assim, tudo o que se pensava sobre fenômenos como aprendizagem, motivação, desenvolvimento, avaliação etc., basicamente, moldava-se pela linguagem que os psicólogos inventaram para descrever as condições experimentais que eles estudaram. Conseqüentemente, aí não havia lugar para intercâmbio com um Dewey, por exemplo, por ser considerado porta-voz de conceitos mais filosóficos do que científicos. Paradoxalmente, desenvolveu-se com isso a imagem de uma forma de extremismo, denominado de psicologização da educação: a psicologia educacional não seria apenas um fundamento, mas o elemento único para a preparação do professor, trazendo consigo os padrões substantivos e metodológicos para toda investigação educacional relevante.

Aquela separação da prática e dos que praticam, nos primeiros tempos, ia mais longe, carregando um certo menosprezo por aquilo que significava prática ou a pedagogia em sala de aula, em geral consideradas não-científicas. O alvo principal dessa discriminação foram os praticantes da educação, professoras em geral, estabelecendo-se até uma separação física de prédios. Em Chicago, Judd isolou do seu departamento de psicologia o setor de formação de professores(as), em parte porque ele acreditava que essa separação contribuiria para assegurar o status científico da psicologia: uma unidade institucional composta sobretudo por mulheres, provavelmente, não granjearia muito prestígio na academia.

Coisas daquela época, em boa parte já superadas. O que pode ainda estar persistindo na área é a crença na idéia de psicologia educacional como fundamento da educação, uma idéia que os psicólogos educacionais, na sua maioria, estão abandonando. Por que motivo? Segundo Calfee e Berliner (1996), considerar a educação apenas como um campo em que se pratica psicologia, ou uma oportunidade em que se aplica o conhecimento científico psicológico, elaborado em outro contexto, deixa de enxergar ao menos duas características da disciplina de psicologia educacional: a primeira é que, ao longo deste século, os psicólogos educacionais desenvolveram uma compreensão mais aprofundada da natureza da tarefa educacional. Ou seja, identificaram nessa tarefa uma grande variedade e complexidade de componentes, com diversos fatores em interação, do que uma pesquisa descontextualizada não poderia dar conta. A título de exemplo, houve consideráveis avanços na compreensão dos efeitos das diferentes tarefas de ensino; quanto aos níveis de processamento da informação por parte dos alunos e sua dependência de aspectos do ensino, enquanto percebidos pelo aluno; e sobre as peculiaridades da motivação no contexto de uma sala de aula (não é um contexto igual ao das empresas, dos esportes, artes etc.). Tais descobertas representam respostas a problemas educacionais autênticos que foram assumidos para pesquisa.

Mas, além disso, os psicólogos educacionais têm desenvolvido formas diversas de colaboração com professores e outros educadores. Desse intercâmbio, que propiciou que sua disciplina se beneficiasse da sabedoria da prática, resultaram novidades no próprio corpo de conhecimentos da disciplina, como aparecem nos manuais mais recentes. Anita Woolfolk, em seu texto de Psicologia Educacional, conclui cada capítulo com citações de experiências reais de professores: como uma leva os alunos a permanecerem em cima da tarefa, mediante um programa de uso de reforçadores; 
como outra faz ligar os textos com a vida; outra, como usa a vida real, os conceitos dos alunos para com eles trabalhar seu conteúdo. Esta forma habitual de exposição praticada pela autora cria nos alunos de Psicologia Educacional a idéia de que é preciso ser criativo na prática (educação é alie, é criatividade); e que, ao mesmo tempo, os princípios e teorias têm real aplicabilidade; e que na aplicação, devem levar-se em conta as nuanças do contexto, do tipo de alunos, as circunstâncias históricas e sociais etc. Em suma, a Psicologia Educacional hoje trabalha menos com os aspectos gerais do que com a aplicabilidade criativa a cada situação.

Eu quero ainda, ilustrar esse aproveitamento da sabedoria da prática, com um exemplo que envolve o conceito de bom ensino ou ensino eficaz, obtido a partir da observação de professores reais. Existem professores com desempenho de alta qualidade em suas funções: os alunos aprendem, produzem e estão satisfeitos e entusiasmados com a disciplina, próximos da motivação intrínseca por ela. Tais professores reais foram entrevistados e observados em sua atuação em classe, e foi possível descrever seus comportamentos específicos em classe e identificar seu corpo de conhecimentos, objetivos, crenças e expectativas, além de outras variáveis pessoais que ajudaram a psicologia educacional a depurar o conceito do que seja bom ensino ou de professor competente, para cuja formação a disciplina pretende contribuir. Foi nesse contexto que se desenvolveu a categorização de professores em: experientes (experts), em oposição a outros, de formação mais recente, principiantes, novatos, ou noviços. Seu modo de enfrentar uma situação, por exemplo, de um aluno-problema varia consideravelmente. O professor expert não é que saiba mais do que um principiante; seu conhecimento é qualitativamente diferente, porque integra os diversos aspectos teóricos entre si e com a prática, enquanto que o principiante faz apelo a um ou outro princípio ou solução, desconectadamente e de modo não-crítico: o aluno indisciplinado simplesmente é mandado para a direção. Segundo diversos autores, poucos chegam ao estágio de expert. Uma publicação periódica, Advances in Research on Teaching, tem relatado pesquisas que descrevem professoras reais dessa categoria, como M. Lampert, da área de matemática.

Em suma, podemos já concluir que tornar-se um psicólogo educacional significa hoje aprender tudo sobre a vida nas escolas. Estabelecer conexões com a prática é tarefa essencial de um psicólogo educacional, inclusive para que as perspectivas teóricas e metodológicas da disciplina possam subseqüentemente ser usadas de modo sensível e humano a serviço daqueles que trabalham nos contextos escolares.

Além dessas duas razões que os autores aduzem para que não se considere a Psicologia Educacional apenas como fundamento da educação, há uma outra consideração a fazer. Segundo Anderson e seus colegas (1996), se nós considerássemos a psicologia educacional apenas como um fundamento da educação, as tarefas dos alunos, nessa disciplina tratada como fundamento, poderiam consistir em leituras, prestar atenção nas aulas, fazer provas, redigir textos - tudo para demonstrar que ocorreu uma assimilação de fatos, conceitos, princípios, teorias, e que tudo isso poderá ser um dia utilizado. A suposição básica é esta: as diversas teorias e princípios seriam apresentados e aprendidos como um corpo de conhecimentos, sem a consideração do contexto, esperando-se que ocorra, posteriormente, a devida aplicação às diversas situações. Se este for o pressuposto, aquelas tarefas parecem razoáveis, adequadas. Elas cumprem o objetivo de transmissão de um corpo de conhecimentos a partir de uma fonte (o professor ou o texto) para um aprendiz que o reproduza. Esse ponto de vista merece ser examinado mais de perto, porque contempla as tarefas dos alunos, cruciais para a aprendizagem e para as transferências dessa aprendizagem para situações 
novas, por ocasião do seu ensino de uma certa disciplina.

Há pelo dois problemas nesse modo assim descrito de se trabalhar Psicologia Educacional na formação dos futuros professores. O primeiro problema consiste num falso suposto: que, tendo aprendido as teorias psicológicas, os princípios gerais, o futuro professor em sua sala de aula, faria aplicações adequadas aos inúmeros casos e situações de sua disciplina. Pense-se em aplicações de teorias cognitivistas de aprendizagem, teorias de motivação e assim por diante. O fato é que os professores não fazem essa aplicação. Primeiro, porque eles mesmos dizem que não sabem como aplicar. Muitos tentam, e acabam acertando após várias tentativas e erros; mas há outros que nessas tentativas adotam aplicações baseadas em inferências viesadas, à revelia da teoria, o que poderá resultar apenas na repetição de práticas anteriores, ou em reutilizar suas crenças pessoais, suas teorias pessoais, quanto àquele tópico de ensino. Muitos fazem inferências de particular para particular: tal estratégia funcionou naquela ocasião, com aquele aluno, aquela turma, logo, pode funcionar com esta outra turma, este outro aluno. O que ele acaba praticando é aquilo que acredita que funciona, ignorando que praticamente cada aluno, cada caso, cada turma tem especificidades que não se repetem.

Mas a raiz mais profunda desse problema está, em parte, na própria natureza das teorias. Em primeiro lugar, a relação entre teoria e aplicação não é linear simples. Já foi demonstrado que práticas tanto saudáveis como espúrias podem derivar igualmente de propostas teóricas falsas. Logo, não se pode argüir pela verdade de uma proposta teórica simplesmente porque sua aplicação prática funciona. Por outro lado, uma mesma prática pode reportar-se a posições teóricas diversas: a aprendizagem por descoberta pode ser decorrência válida da teoria de Piaget, da de Vygotsky e da Skinneriana; no entanto, estas duas últimas posições são, em outros aspectos, incompatíveis com a teoria psicogenética. As práticas escolares montessorianas são também compatíveis com Piaget, embora suas teorias sejam bem diferentes. Assim, mesmos métodos de ensino podem ser compatíveis com diferentes pressupostos psicológicos. Portanto, não há uma correlação unívoca e necessária entre certa teoria e aplicações práticas.

Além disso, as teorias são, por natureza, genéricas, não-específicas, por não contemplarem explicitamente a infinidade de casos potencialmente abarcados por ela e nem, a cada situação, darem conta das suas inúmeras peculiaridades. Isto é, há uma considerável distância entre qualquer teoria e a situação real de qualquer sala de aula, em função dos inúmeros componentes que tornam essa situação muito complexa e imprevisível, em que os eventos se sucedem rapidamente, às vezes ao mesmo tempo. Os professores precisam preparar-se para essa complexidade e para um alto grau de incertezas. Tal preparação exige algo mais do que simplesmente tomar conhecimento das teorias e dos princípios psicológicos. Esse tipo de fundamento não é suficiente, porque não se pode esperar que possam aproveitar delas em sua prática. Há cerca de 100 anos, William James, escrevendo para professores, dissuadiu-os a que buscassem diretamente na psicologia, ciência da mente, programas definidos, esquemas e métodos de ensino. Estas últimas coisas pertencem ao domínio da arte e dependem da genial idade de cada professor. Para ele, a psicologia é de caráter mais proscritivo, dizendo o que não se deve fazer, mais do que o que se deve fazer, ou seja, não é prescritiva. O que permanece verdadeiro dessa aula de William James é que, para se aplicar na prática o conjunto de conhecimentos teóricos da psicologia, é preciso adquirir algo mais do que esses conhecimentos teóricos.

Em síntese, se a Psicologia Educacional não pode ser considerada como fundamento para a 
prática do ensino pelos motivos expostos, como se pode então descrever sua função da formação dos futuros professores? De que modo ela deve ser tratada nos cursos de licenciatura?

Um grupo de professores de Psicologia Educacional e pesquisadores de renome (Linda Anderson, Pintrich, Blumenfeld, e outros colaboradores: Anderson et aI., 1995) estão propondo uma verdadeira (e nova) função da psicologia educacional na formação dos professores. Suas reflexões e propostas, frutos de suas próprias experiências como professores, têm sido alvo de críticas e sofreram retoques por certos autores da área educacional. Mas, ao mesmo tempo, tais posições têm sido apoiadas e assumidas por muitos outros psicólogos, em publicações diferentes: Calfee e Berliner, o Handbook editado em 86 por Wittrock, o recente Handbook of Teacher Education, editado por Murray; Brophy; Shuell; Woolfolk, entre os mais conhecidos. Considero, portanto, uma forte tendência contemporânea, que cria corpo, em função das justificativas que a apóiam e do seu notável alcance educacional. Numa formulação simples e abrangente, segundo Anderson et al. (1995), a função da psicologia educacional é fazer os futuros professores desenvolverem uma perspectiva psicológica útil. O conceito de perspectiva quer dizer lentes, modos de ver, que se desenvolvem mediante os conhecimentos construídos socialmente nessa disciplina de psicologia; e que terá real utilidade, em função do modo como a disciplina será tratada.

Antes de tudo, é útil trazermos à memória neste momento, a experiência de muitos de nós quanto às expectativas iniciais que os acadêmicos trazem quanto a essa disciplina. Tais expectativas precisam ser levadas em conta, quando se trata de desenvolverem aquela perspectiva psicológica útil. Temos alunos e alunos. Muitos adentram essa disciplina com esta idéia: de psicologia eu já sei o suficiente para ensinar; não preciso de quase mais nada; e o que consta desse programa não irá acrescentar nada de importante para a prática. Já outros, sobretudo aqueles que ainda não se definiram pelo exercício futuro do ensino, esperam que o professor trate de assuntos interessantes e atuais de psicologia, que explique casos curiosos e raros que a mídia costuma levantar de forma superficial. Problemas do tipo: regressão por hipnose à fase da vida no útero materno; se homossexualidade é de origem genética ou o quê? Casos de dupla personalidade de grandes criminosos. Outros ainda trazem casos de sua experiência pessoal ou familiar, querendo uma resposta e uma solução, ali na sala de aula. Já entre os mais preocupados com o ensino, há quem levante questões como esta: como é que se consegue controlar uma turma para que todos prestem atenção, façam tarefas, produzam e aprendam? Como vou motivar alunos desinteressados por minha matéria? Ou como manter uma motivação já existente? É também muito comum nós sermos consultados quanto a problemas prementes e particularizados, como o de algum aluno totalmente apático em sua classe, ou de outro que é resistente-agressivo, ou que parece ser hiperativo. E assim por diante. Todas essas questões estão revelando, por igual, preocupações de natureza prática por parte desses alunos, mas esperam que o professor lhes forneça uma receita, uma solução ad hoc que, ao lhes ser fornecida, muitas vezes é seguida de desinteresse pelo restante da matéria.

Nem sempre podemos ou devemos atender a tais expectativas de alunos. Em outros casos, a compreensão de tais problemas e as estratégias para sua solução aparecerão ao longo da matéria. Mas de alguma forma devemos ser responsivos à sua preocupação com problemas educacionais autênticos. Ora, essa responsividade deve começar por ajudá-los a construir de modo significativo todos os conteúdos que tradicionalmente compõem nossa disciplina, ou seja, aprendizagem, cognições; desenvolvimento humano; diferenças individuais; motivação; avaliação; grupos 
especiais de alunos. Conteúdos relevantes que são, eles apresentam-se em evolução incessante: há um aumento quantitativo e qualitativo de dados, reelaboração de teorias antigas, surgimento de novas, o que exige de todos nós uma contínua atualização quanto à literatura.

Para começar, nós mesmos temos que valorizar esse corpo de conhecimento acumulado e mostrar que o valorizamos, pela busca incansável de atualização: os futuros professores precisam sentir que nós somos os primeiros a acreditar na psicologia, e que a praticamos em nossa própria disciplina. A seguir, com os métodos que se adotarem, precisam processar esse acervo de informações científicas e deixem de se contentarem com os conhecimentos sumários, imprecisos, indiscriminados que já possuam e que os levam a repetir-se a si mesmos ou simplesmente a copiar as experiências que tiveram com seus próprios mestres em uma vida inteira como alunos. Em suma, ser bem informado quanto aos conteúdos de psicologia é condição necessária, embora não suficiente, para que os futuros professores desenvolvam uma perspectiva psicológica útil no exercício de sua função.

Como primeira conseqüência desse nível de informação processada, eles saberão levantar não apenas aquelas questões de natureza imediatista, mas sobretudo as questões de fundo, aquelas que afetam diretamente o ensino e a educação em sala de aula. Boas soluções têm seu começo com o levantamento das questões corretas.

Shuell (1996a), em artigo recente, sugere que todo professor de uma matéria específica deve ser capaz de levantar, pelo menos, questões como estas:

- Que tipos de problemas ou necessidades (emocionais, sociais, desenvolvimentais) meus alunos estariam tendo? Até que ponto o ambiente do lar ou necessidades especiais deles estariam afetando suas autopercepções e o seu rendimento na escola? E como eu poderia ajudá-los nessa questão?

- Quais são os conhecimentos prévios para esta matéria, suas crenças, seus sentimentos quanto ao tópico que precisariam aprender ou desenvolver, em termos de conhecimentos ou habilidades?

- Até que ponto esta classe é semelhante e em que aspectos é diferente das demais? Em quanto isso afeta meu ensino, exigindo adaptações, e quais?

- É hora de fazer avaliação? Qual e como? Com que cuidados?

- Que teoria de aprendizagem (construtivista, operante...) é mais relevante para o conhecimento, a compreensão, a habilidade que os alunos estão buscando adquirir? Por quê?

- E que tipos de tarefas devo dar aos alunos que, com mais probabilidade, promoverão as atividades mentais necessárias e desperte a motivação desejada, em direção aos objetivos pretendidos?

Dar uma solução adequada a cada uma dessas questões exige, além de uma competência quanto ao conteúdo específico de sua própria matéria, um bom conhecimento desses tópicos de psicologia educacional. Mas exige ainda um outro tipo de competência, que tem muito de mie, criatividade, engenhos idade e experiência e que cobra sobretudo muito trabalho. Ensinar é também questão de técnica. No seu dia-a-dia, o professor de qualquer disciplina terá que dar respostas online, em tempo real, fazer julgamentos profissionais, empregar uma espécie de raciocínio clínico, e cumprir uma série de funções como a de criar uma tarefa nova e adequada, explicar, dar apoio, motivar, não dar a resposta certa... O grande objetivo é que, um dia, ele possa atingir o nível de 
professor expert, que descrevemos anteriormente; que ele se torne um experiente adaptador, um participante na comunidade de busca, que chegue a compreender os fenômenos, suas origens, seus componentes e, sobretudo, saiba que cursos de ação se podem tomar, de modo criativo, personalizado, adaptado a cada caso.

Para isso, a disciplina de psicologia educacional deve ser desenvolvida com a característica de real utilidade para o desenvolvimento dessas habilidades; e os alunos devem perceber, sentir essa possibilidade de utilização e preparar-se devidamente para essa utilização. O que fazer para que isso aconteça?

Reportando-me ao trabalho daquele grupo de pesquisadores, citados (Anderson et al., 1995), vou extrair dele duas sugestões ou propostas que julgo prioritárias, e que incidem sobre como trabalhar os conteúdos atualizados de Psicologia Educacional com alunos de licenciatura. Eu as exponho aqui com a finalidade de fomentar reflexão e debate, e até propiciar intercâmbio de experiências, A idéia básica consiste em que, no decorrer da disciplina de Psicologia Educacional, se adotem pelo menos estas duas grandes estratégias: uma relativa às crenças e conhecimentos prévios dos alunos de licenciatura e outra, quanto à ligação com a vida real de sala de aula que irão enfrentar.

I. Que os alunos de Psicologia Educacional possam revelar suas crenças e conhecimentos prévios acerca dos tópicos dessa disciplina. Todo aluno entra para o curso de formação de professores com determinadas crenças sobre aquela matéria, sobre aprendizagem, motivação, sobre aluno, sobre ensino etc. Às vezes, são crenças muito bem estabelecidas e que formam redes de itens interligados, e alimentadas por experiências pessoais e interações com colegas. Neste caso, são altamente resistentes a mudanças. O pior é que, segundo pesquisas, tais crenças funcionam como filtros, que comprometem ou até bloqueiam a compreensão de novas informações, mesmo quando estas, ao contrário das crenças, têm sólida base científica. Em relação a ensino e aprendizagem, fortes crenças se formam exclusivamente com a própria experiência enquanto alunos, Crenças do tipo: que aprender consiste em assimilar um conteúdo, e que ensinar é transmitir; que motivação o aluno já deve trazer de casa, e o professor pouco pode fazer; que há alunos que simplesmente não são capazes de aprender. Tais alunos entram para a disciplina de Psicologia Educacional com essas crenças e dela saem com as mesmas crenças intactas. A sugestão de todos os especialistas na área é que não se pode trabalhar adequadamente qualquer conteúdo, a menos que se levem em conta tais crenças; e que, a seguir, elas se transformem ou se abandonem, quando necessário. Esse processo começa com procedimentos que façam os alunos exporem suas crenças pessoais. Existem diversas maneiras pelas quais os professores podem consegui-lo: através de simulações, narrativas de seus modos de agir, redação com comentários, ou da própria fala e de ações. Um modo que pode ser posto em prática é delinear tarefas que exijam que os alunos expliquem abertamente a argumentação e as teorias subjacentes a suas ações e decisões. Eles serão, em seguida, expostos a pontos de vista contrários, extraídos das teorias ou de resultados de pesquisas, do que resultará um conflito cognitivo. Quando isso ocorrer, desde que naquele contexto todas as idéias sejam respeitadas e os indivíduos encorajados a expressar e a revisar publicamente seu modo de pensar, essa expressão pública pode propiciar o desenvolvimento pessoal do conhecimento. De que valeria expor os alunos a toda sorte de novos conteúdos, teorias, princípios - literatura atualizada - se eles se mantiverem refratários a essas idéias novas, em função de crenças concorrentes? Daí ser imperiosa essa primeira providência de natureza psicológica, que deverá ser retomada praticamente 
a cada novo grande tópico que se focalize na disciplina.

II. Boa parte das tarefas (não necessariamente todas), destinadas a fazer os alunos trabaIharem conteúdos de Psicologia Educacional, deve ter a característica de autenticidade, $e$ essas tarefas devem também representar tanto quanto possível a complexidade da situação de ensino. Trata-se aqui das tarefas ou atividades mediante as quais os nossos alunos irão aprender. Há uma linha de pesquisas que forneceu resultados segundo os quais na escola os alunos não aprendem adequadamente um conjunto generalizável de conhecimentos, de modo alheio ao contexto em que será utilizado. Neste sentido, são hoje freqüentem ente adotadas por muitos autores expressões como "cognição situada", "aprendizagem autêntica", em oposição a uma aprendizagem escolar puramente acadêmica, descomprometida em relação às situações de contexto real, nas quais se deveriam usar aqueles conhecimentos e habilidades. No caso dos futuros professores, o contexto dos conteúdos de psicologia é sua sala de aula, uma determinada disciplina, com aquela turma (cada turma tem um perfil todo próprio). Se o objetivo é propiciar conhecimento útil sobre idéias importantes de psicologia, deve-se fazer os alunos trabalharem aquelas idéias numa variedade de situações, ajudando-os a ver o que é semelhante e o que é diferente nas situações, e como a utilização das idéiaschave varia conforme a situação. Desta forma, os conhecimentos teóricos assumem o que se pode chamar de validade ecológica. A repetição da experiência com as idéias em situações diferentes cria uma compreensão mais rica e mais estável dessas idéias, com maior probabilidade de serem disponíveis em situações não-familiares e mesmo complexas que possam ocorrer no futuro. Em suma, a qualidade das aprendizagens de psicologia dependerá acentuadamente dessas pistas e do apoio cognitivo inerentes aos contextos e às atividades (Shuell, 1996b).

O já citado manual de Psicologia Educacional, de Anita E. Woolfolk, cumpre tal exigência e fomenta essa prática nos professores: ao final de cada tópico, a autora propõe uma meia dúzia de casos-problema da situação escolar, cuja solução exige o emprego dos conceitos e teorias recémdesenvolvidos. Quando o aluno se dedica a trabalhar os problemas daquela forma, sua aprendizagem está se tornando autêntica, contextualizada, além de abrir caminho para outras possíveis aplicações. Mas sempre é preciso ter cautela com supergeneralizações a partir de estudos de casos; eles podem ser limitantes, por conterem apenas algum aspecto da realidade de sala de aula. Isso levaria a aplicações distorcidas, como se todos os casos fossem iguais. Por outro lado, praticar com muitos casos diferentes da realidade pode não ser viável face às limitações da carga horária concedida para cobrir os principais conteúdos relevantes da disciplina. Isto nos deixa forçosamente em algum lugar aquém do ótimo desejado, mas nos limites do possível, em termos de consideração das diversas situações de aplicação. Enfim, pautando-nos pelo modelo dessa autora, nós todos podemos adotar e desenvolver esse método, em sala de aula, introduzindo discussão, redação e outros procedimentos, tais que representem verdadeiro exercício de aplicação e generalização, com o número de casos possível.

Na mesma direção, Shuell (1996a) relata que, em sua disciplina de Psicologia Educacional, adota o método de projeto, em que um grupo de alunos desenvolve, ensina, avalia e critica uma mini-lição de sua própria matéria (por exemplo, história), apresentada a outros colegas. Não é seminário. E o objetivo explicitado não é o de treinar a prática de ensino para os alunos adquirirem proficiência, mas sim para praticarem a relação entre determinado tópico teórico de psicologia e sua 
aplicação ao ensinarem sua matéria específica, como seria a de proporcionar diversas formas de feedback, após uma performance oral de alunos numa situação de argüição. Se o aluno constrói os conhecimentos por meio de ações sobre esse objeto, e de forma socializada, tais atividades de aplicação otimizam sua aprendizagem de psicologia. Aqui no Brasil, constatamos um paradoxo no treinamento dos alunos de licenciatura: as disciplinas de Prática de Ensino ou Didática raramente (ou nunca) exploram tópicos já vistos de Psicologia, aplicando-os de modo prático. Algum conhecimento de psicologia sequer é mencionado. Isto porque os próprios professores dessas disciplinas não são tão atualizados e podem mesmo ter prevenção contra a psicologia. E por outro lado, nós, da psicologia educacional, ficamos apenas com os aspectos teóricos, evitando entrar em exercícios práticos. Daí resulta um considerável espaço vazio que, além de tornar a nossa disciplina alvo de críticas por ser exclusivamente teórica, o aluno não aprende como traduzir aqueles princípios para a realidade do ensino de suas matérias específicas.

Em poucas palavras, acolhendo sugestão de Collins, citado por Shuell (1996b), nas aulas de Psicologia Educacional os alunos devem: (a) aprender as condições em que se aplicam aqueles conhecimentos; (b) ser expostos a situações que propiciem invenção, criatividade; (c) enxergar as implicações do que estão aprendendo; e (d) ter conhecimento das estruturas de contexto apropriado para seu uso.

Como se pode facilmente concluir, uma vantagem apreciável de tal método de trabalho é que ele faz desenvolver o tipo de professor que Schõn denomina de professor reflexivo - aquele que pensa sobre seu trabalho, analisa suas soluções, inventa, é intelectualmente curioso, o que, de resto, supõe que ele seja socialmente comprometido e até apaixonado pela sua função e que não se contente com soluções pré-programadas. Ao longo do tempo, irá mesmo surgir uma compreensão progressivamente melhor das teorias e princípios psicológicos, em seus meandros e detalhes, em função dessa vida de estudo, de reflexão e de aplicações. Um professor competente, expert, é aquele que integra os diversos conhecimentos entre si, sabe fazer o processo vertical de integração entre teoria e prática, resultado de uma existência devotada apaixonadamente a seu trabalho.

Há uma providência adicional a ser tomada, que pode facilitar a implementação dessas propostas metodológicas. Segundo alguns autores, um dos grandes obstáculos ao desenvolvimento, nos futuros professores, do hábito da reflexão sobre o próprio ensino é o solacionismo do professor de Psicologia Educacional, tanto em relação a seus colegas como em relação aos professores das demais disciplinas pedagógicas nas licenciaturas. Resultados melhores se conseguiriam, inclusive em termos de crescimento e desenvolvimento pessoais, com a socialização das experiências, conhecimentos e idéias de todo esse corpo de formadores, o que se reconhece ser uma tarefa custosa e exigente.

Mas, por outro lado, pode-se supor que nenhum professor de Psicologia Educacional aceita a estagnação, ou o continuismo de práticas obsoletas. Verifica-se em toda parte uma inquietação e até um desconforto diante do modo frágil como são formados os futuros professores. Para sairmos desse estado, cada um de nós, professores de Psicologia Educacional, deve propor para si próprio atingir grandes metas, as mais altas possível, em relação aos alunos das licenciaturas: trabalhar com os melhores autores; com o melhor método de ensino contextualizado; com a mais elevada crença de que podemos formar professores altamente competentes, justamente por haverem desenvolvido uma perspectiva psicológica útil em nossa disciplina. 


\section{Referências}

Anderson, L. M.; Blumenfeld, P.; Pintrich, P. R.; Clark, C. M.; Marx, R. W.; e Peterson, P. (1995). Educational Psychology for teachers: Refonning our courses, rethinking our roles. Educational Psychologist. 30 (I); 143-157.

Calfee, R. C. e Berliner. D. C. (Eds.) (1996). Handbook of Educational Psychology. New York. Simon \& Schuster Macmillan.

Shuell, T. J. (1996a). The Role of Educational Psychology in the Preparation of Teachers. Educational Psychologist. 31(1); 5-14.

Shuell, T. J. (1996b). Teaching and Learning in a Classroom Context. In F.B. Murray (Ed.) The Teacher Educator's Handbook. San Francisco, Cal., Jossey-Bass Publishers; 726-764.

Wittrock, M. C. (1992). Empowering Conception of Educational Psychology. Educational Psychologist. 27(2); 129-141.

Woolfolk, A. E. (1995). Educational Psychology (6th ed.) Boston: Allyn \& Bacon. 